\title{
Mindfulness in Treatment Approaches for Addiction - Underlying Mechanisms and Future Directions
}

\author{
Annika Rosenthal ${ }^{1} \cdot$ Michael E. Levin $^{2} \cdot$ Eric L. Garland ${ }^{3} \cdot$ Nina Romanczuk-Seiferth $^{1}$ (D)
}

Accepted: 28 April 2021 / Published online: 15 May 2021

(C) The Author(s) 2021

\begin{abstract}
Purpose of Review While the treatment of addictive disorders proves to be challenging, new treatment approaches that evolved around the concepts of mindfulness and acceptance have been utilized and investigated in recent years. Our goal is to summarize the efficacy and possible underlying mechanisms of mindfulness-based interventions (MBI) in addictive disorders.

Recent Findings Various meta-analyses have suggested that MBIs show clinical efficacy in the treatment of addictive disorders. Considering the factors that impact addictive disorders, MBIs have been indicated to augment responsiveness to natural rewards in contrast to addiction-related cues as well as to increase top-down cognitive control, decrease subjective and physiological stress perception, and enhance positive affect.

Summary In summary, MBIs hold promise in treating addictive disorders while larger randomized controlled trials with longitudinal study designs are needed to confirm their utility. Newest clinical endeavors strive to enhance the clinical utility of MBIs by augmentation or personalization.
\end{abstract}

Keywords Mindfulness $\cdot$ Addiction $\cdot$ Mechanisms $\cdot$ Intervention $\cdot$ Reward $\cdot$ Stress

\section{Introduction}

The hallmark of substance use disorders as well as behavioral addictions is habitual or even compulsive behavior such as recurrent use of drugs or repetitive performance of activities such as gaming or gambling. Individuals continue this behavior despite the harm it inflicts on themselves and others [1]. Various mechanisms are involved in the emergence, progression, and maintenance of addictive disorders and treatment is vastly

This article is part of the Topical Collection on New Treatment Approaches in Addiction

Nina Romanczuk-Seiferth

nina.seiferth@charite.de

1 Charité - Universitätsmedizin Berlin, corporate member of Freie Universität Berlin and Humboldt-Universität zu Berlin, Klinik für Psychiatrie und Psychotherapie, Charité Campus Mitte, Charitéplatz 1, 10117 Berlin, Germany

2 Department of Psychology, Utah State University, Logan, UT, USA

3 Center on Mindfulness and Integrative Health Intervention Development, University of Utah College of Social Work, Salt Lake City, UT, USA difficult, which is reflected by high rates of relapse [2, 3]. Traditional treatment entails, among others, patient group therapy or cognitive behavioral therapy (CBT) [4]. In addition, contextual CBTs or so-called third-wave treatments such as mindfulness-based relapse prevention (MBRP) or mindfulnessoriented recovery enhancement (MORE) have been specifically tailored to be applied in the context of addictive disorders, while acceptance and commitment therapy (ACT), which employs an acceptance and mindfulness approach that integrates values and broader behavior change strategies, has been applied in addictive disorders in the recent years [5]. To clarify, while all MBIs centrally employ mindfulness meditation practices, MBRP additionally focusses on cognitive behavioral relapse prevention treatment [6], while MORE additionally provides training in reappraisal and savoring skills [7]. These third-wave treatments share a common emphasis on the use of mindfulness techniques that might target several aspects of addiction such as the reward value of the behavior or drug of choice, conditioned automatized behavior, or the reinforcement of alternative rewards [8, 9]. Opposed to standard behavioral therapy that mainly aims to change and regulate cognition, mindfulness-based interventions (MBI) operate through the alteration of awareness and perception towards cognizance of the "present moment" without 
judgement [10]. Research has suggested that MBIs are effective in treating addictive disorders in comparison to standard treatment [11-13].

Furthermore, the focus on the efficacy of MBIs as addiction interventions has been broadened to explore the underlying effects of these interventions on cognitive, affective, and neural processes that drive addictive disorders. Therefore, we aim to give a qualitative overview of efficacy studies as well as research that investigates the underlying mechanisms of substance-related and behavioral addictions that are targeted by MBIs. In addition, we summarize novel approaches to MBI such as augmentation by pharmacological interventions as well as neurostimulation.

\section{Mindfulness}

Mindfulness is a concept that is of eastern traditional origin and is linked to the practice of mindfulness-mediation [14]. It has been described as a state of consciousness in which one pays "attention in a particular way: on purpose, in the present moment, and non-judgmentally" [15]. In other words, this state is characterized by a non-critical, attentional focus on current experiences, $\operatorname{cog}$ nitions, perceptions, and feelings. In addition, mindfulness can also be described in terms of a trait that has shown to be increased with practice of mindfulness-meditation [16].

First applied for chronic pain, Mindfulness-Based Stress Reduction (MBSR) was the first MBI that was applied in a secular medical setting. Treatment success and positive effects on mood and anxiety led to the development of MBIs utilized for psychiatric disorders and later specifically tailored to addictive disorders [17]. As of today, various MBIs for the treatment of addiction have been developed and investigated [17] [7]. In addition, mindfulness is conceptually integrated in some thirdwave approaches in psychotherapy which have also been adapted for the treatment of addictions, like dialectical behavior therapy (DBT) [18]. This also applies to ACT, which is focused on psychological flexibility processes that orient to facets of mindfulness including acceptance, cognitive defusion, self-ascontext, and flexible attention to the present [19].

Due to the recent interest in MBIs, their therapeutic potential for the treatment of addictive disorders has been explored through several reviews and meta-analyses. The following section aims at giving an overview of the conclusions related to the efficacy of MBIs on substance-related and behavioral addictive disorders (Table 1).

\section{Efficacy of MBIs}

A systematic review and meta-analysis by Li et al. [20] examined the results of 42 studies on the efficacy of MBIs on substance use. The authors concluded that the efficacy of MBIs was promising as indicated by generally producing larger improvements relative to control interventions such as treatment as usual (TAU) or CBT. These findings related to clinical outcome measures such as abstinence, craving, and quantity of use as well as substance-related problems, with rather variable small to large effect sizes favoring MBIs. Among MBIs, MORE produced the largest effect sizes observed in this meta-analysis. In line with that, another meta-analysis of 9 RCTs evaluating MBRP specifically concluded that in comparison with control conditions, MBRP yielded significantly better results in terms of withdrawal and craving symptoms (SMD = $-.13)$ as well as negative consequences of substance use (-.23) [21]. Effects of MBRP on substance use frequency or relapse, however, did not differ from standardized treatment approaches including CBT and TAU [21]. Broadly reviewing the efficacy of MBIs on substance-related and behavioral addictive disorders, a review of 54 randomized controlled trials (RCT) determined MBIs to be effective, but with unclear long-term outcomes and with greater results tending to be found when MBIs were combined with TAU [13]. The authors further conclude that MBRP and MORE were the most effective intervention programs. Tying in with the systematic review by Li et al. [20], a more recent systematic review concludes MBIs to be as effective, and in some cases more effective than control interventions that were mostly comprised of standard treatment approaches [22]. MBIs in the treatment of tobacco use specifically were assessed by one meta-analysis that emphasized that the reviewed evidence was characterized by poor quality and small sample sizes [23]. Over the 10 reviewed studies, no significant improvements on tobacco use outcome measures could be detected in comparison to control treatment approaches or when aggregating effects across $6 \mathrm{RCTs}(\mathrm{OR}=2.52$ favoring MBIs, $95 \% \mathrm{CI}=.76,8.29)[23]$.

The effect of MBIs and ACT explicitly on alcohol use disorder (AUD) was concluded to be comparable to other existing treatment approaches in another meta-analysis [12]. Results furthermore indicated the utility of MBIs and ACT in the treatment of comorbid mental health conditions such as depression or other affective disorders that often occur in conjunction with addictive disorders. A meta-analysis of 10 RCTs comparing ACT to other active treatments (e.g., TAU, CBT) found significant small effect sizes favoring ACT on substance use $(g=.29-.45)$ [5]. A more recent review of 22 studies concluded that ACT alone or in combination with other treatments was effective in reducing substance use [24].

Maynard et al. [25] examined the efficacy of MBIs in the treatment of gambling disorder and included seven studies in their meta-analysis. Moderate to large effect sizes of the interventions on clinical outcome measures indicate MBIs to be effective for gambling disorder patients. Although MBIs are generally considered effective and safe in the treatment of behavioral addictions, only a small number of clinical trials have investigated them in this context [26]. In a recent RCT, 


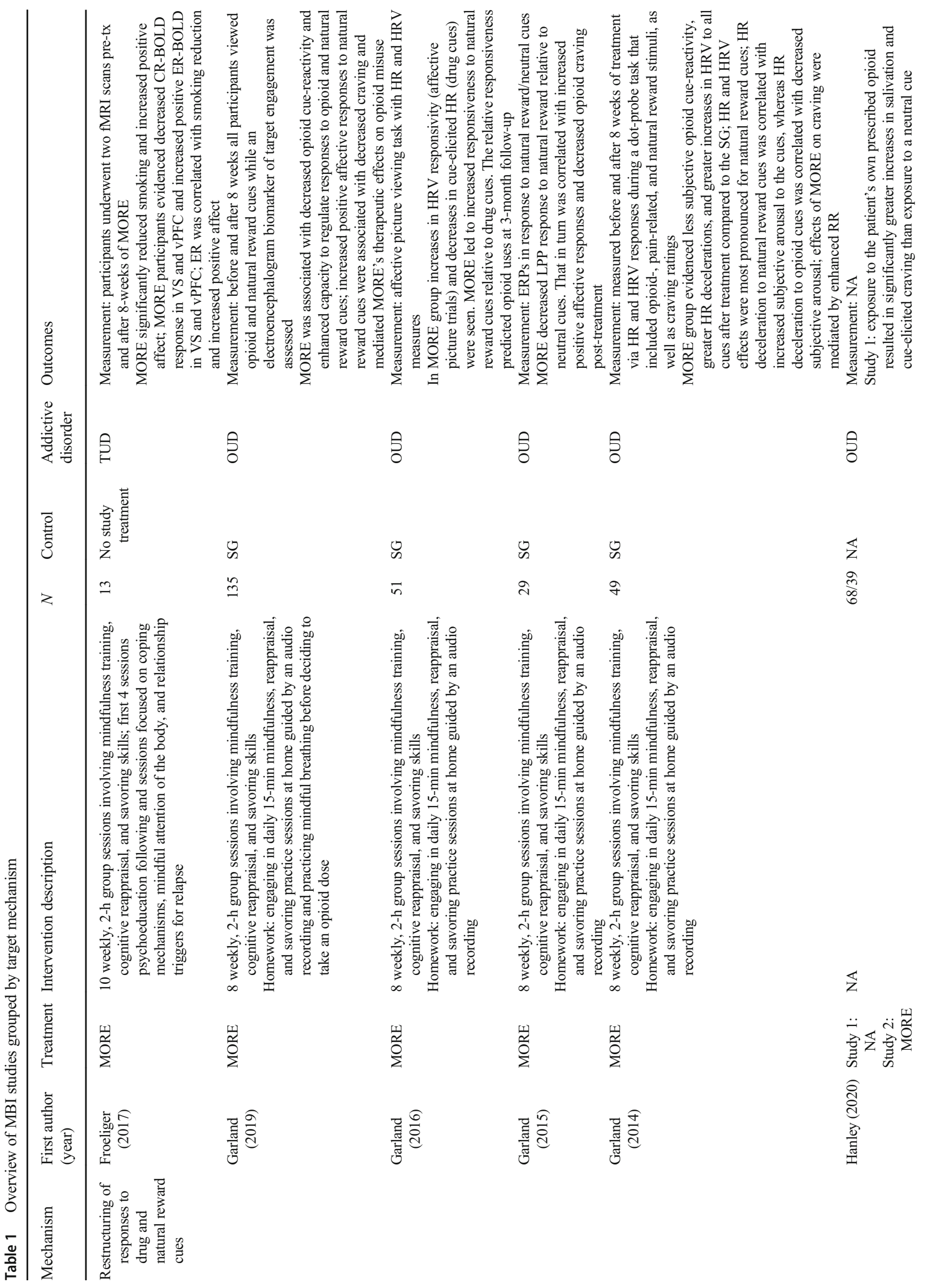




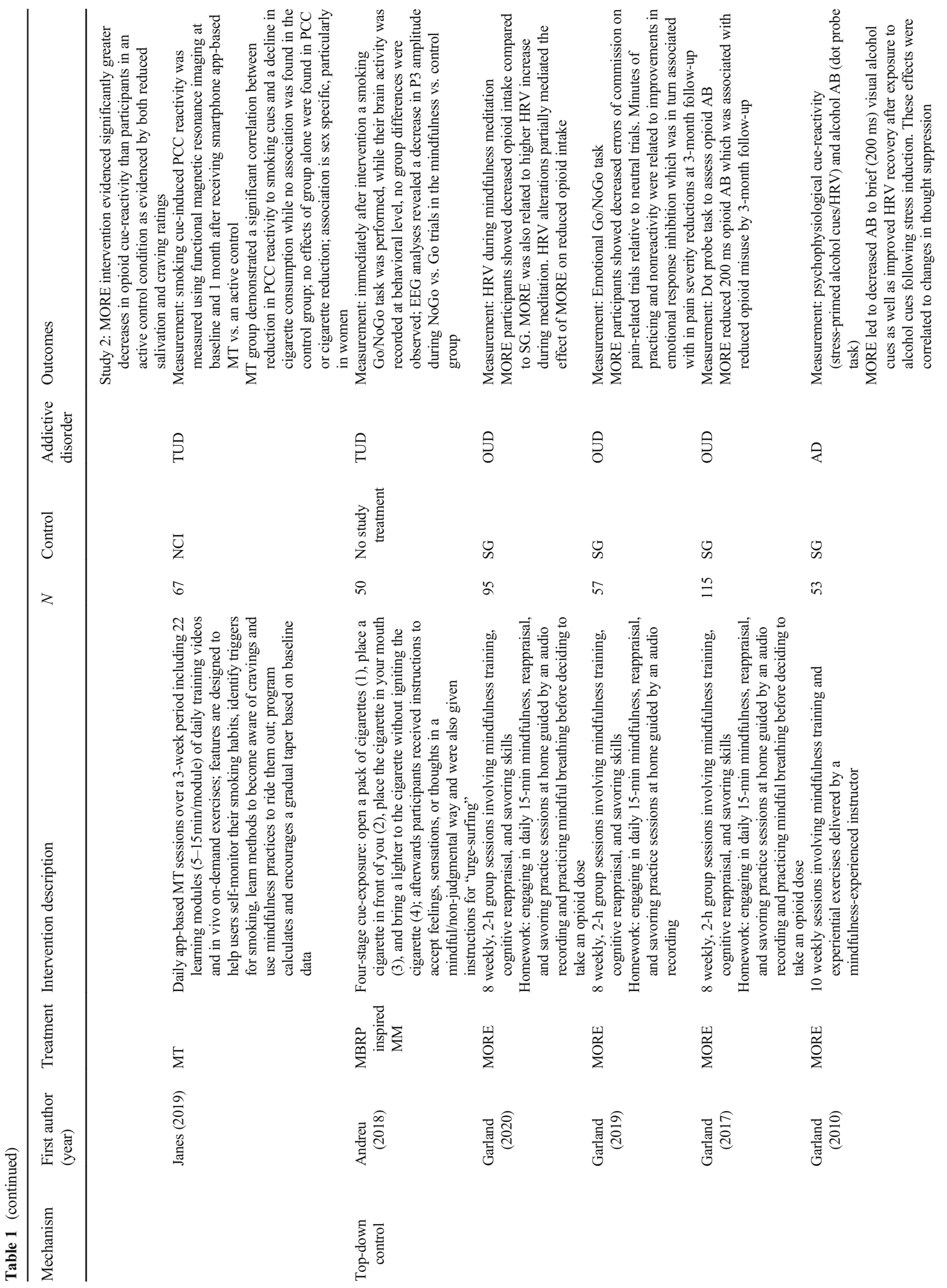




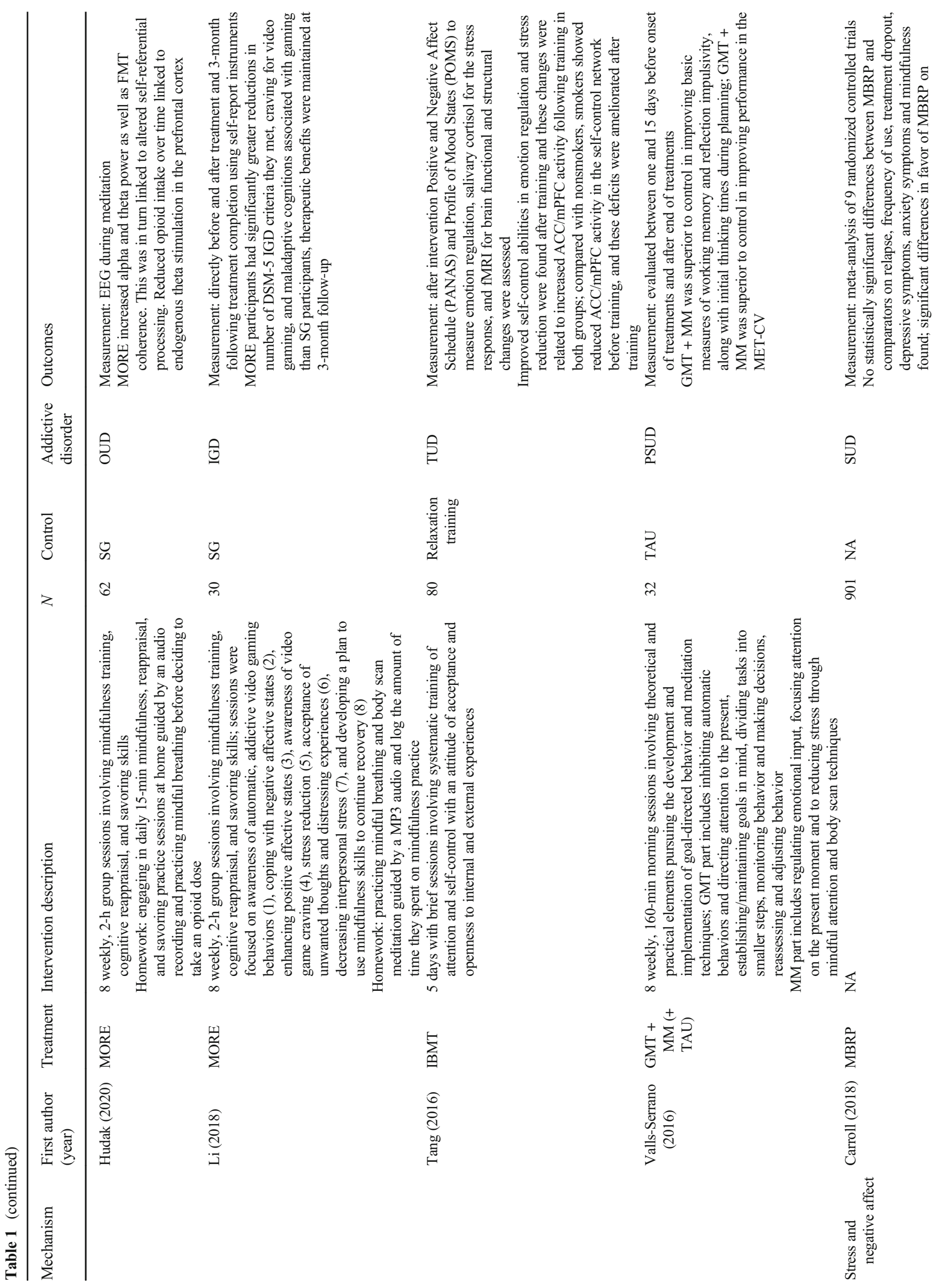




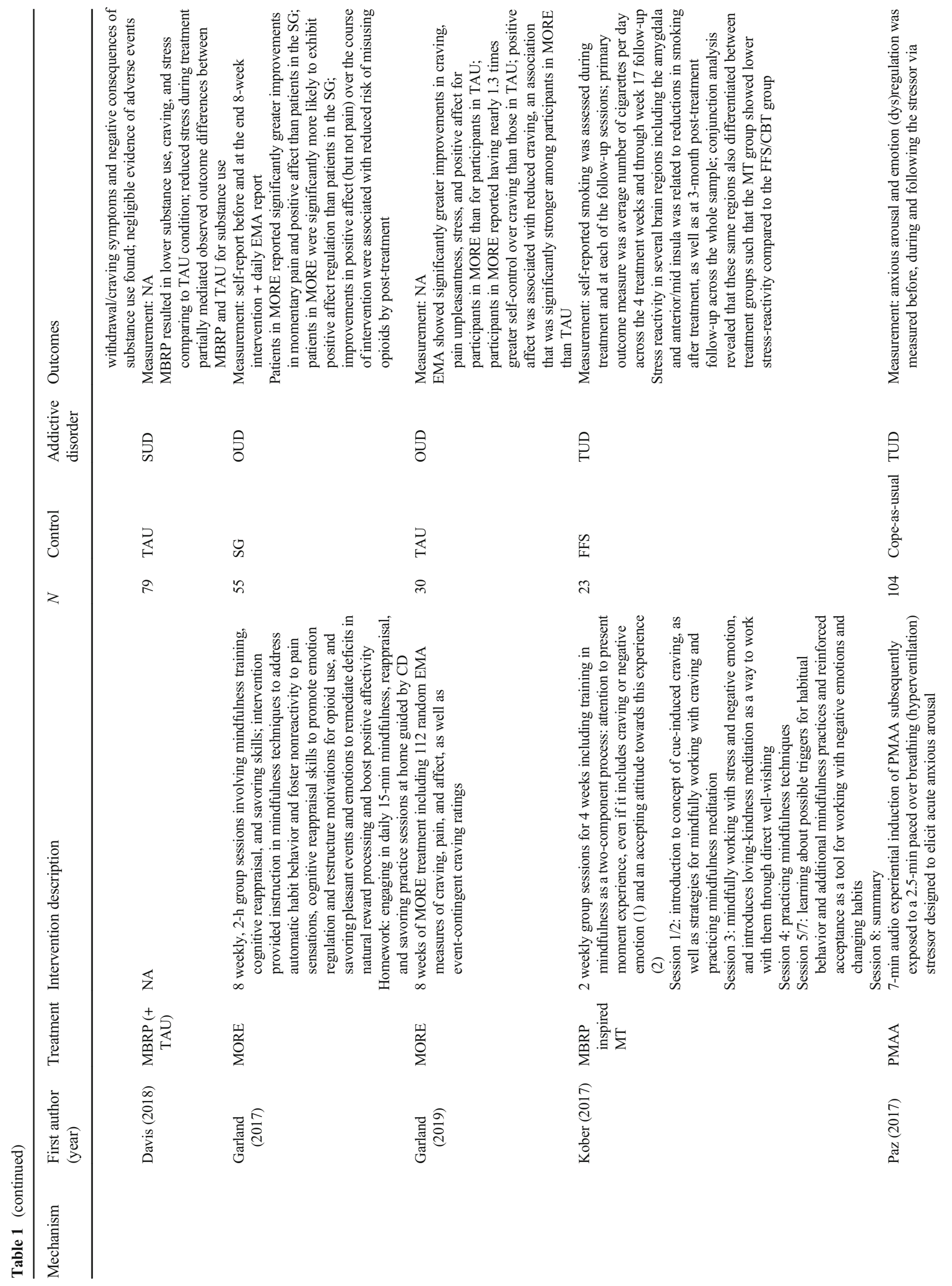




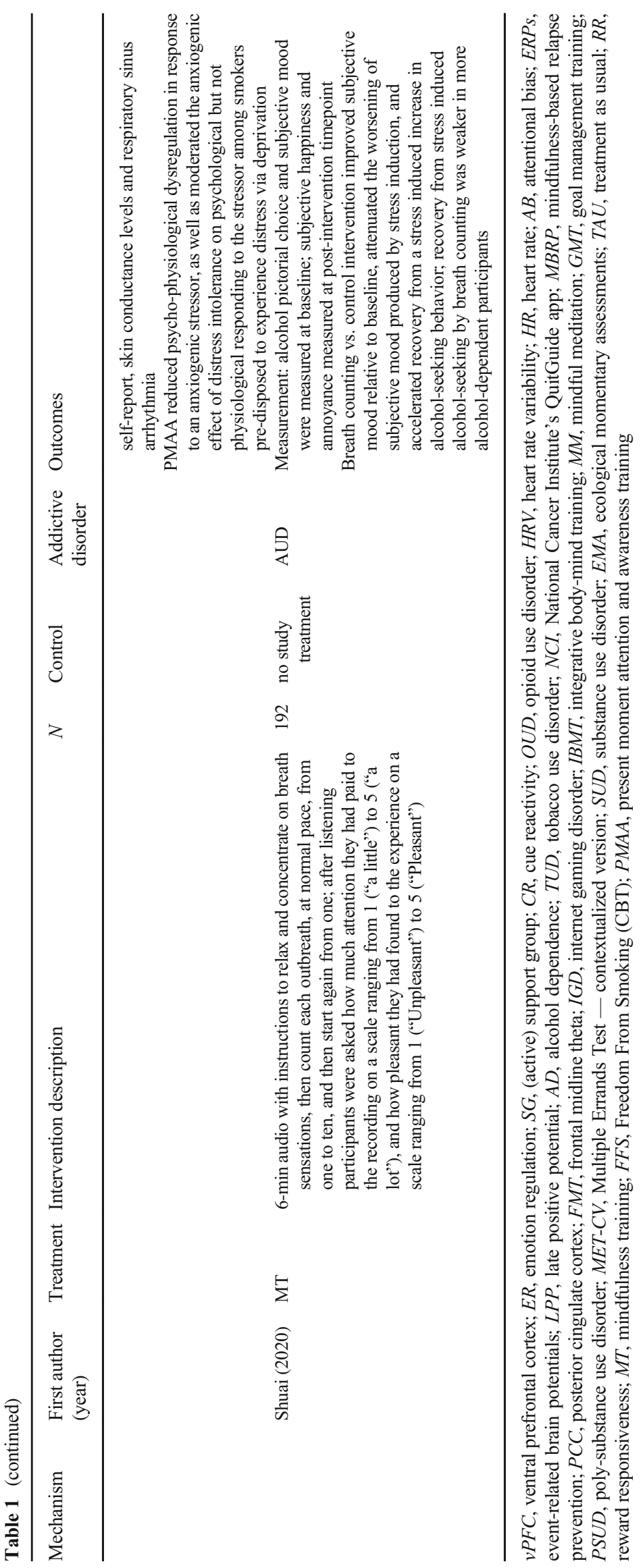


an MBI intervention was compared to CBT approaches in a group of patients with problem gambling [27]. The authors state that the MBI was as effective as TAU and more efficient than a manualized CBT intervention. Investigating the effect of an MBI in a sample of students with excessive smartphone use, the authors found smartphone use to be significantly reduced after treatment compared to a control group [28].

Although not classified as addictive disorders by ICD-11 or DSM-5, problematic pornography use as well as binge eating share some criteria with SUD and behavioral addictions such as lack of control over habitual or even compulsive behavioral patterns [29] [30]. Meta-analyses showed that ACT was effective in reducing pornography viewing time as well as improving measures of quality of life. Furthermore, MBIs were moderately to largely effective in the treatment of binge eating [31] [32]. Further research in behavioral addictions has been limited so far to the investigation of trait mindfulness [33] and case-reports [34].

Even though generally favorable, some meta-analyses conclude that MBIs are comparable but not superior to existing treatment approaches. In addition, Witikiewitz et al. found that, possibly due to participants' struggles with regular mindfulness practice, compliance rates are lower than those of relapse prevention [35]. Overall, these results indicate, especially in the context of behavioral addictions, the need for larger confirmatory efficacy trials with high quality methodological controls to determine the efficacy of MBIs in the treatment of addiction.

\section{Addictive Disorders}

SUD and other addictive disorders are often marked by a gradual shift from goal-directed behavior mediated by the positive reinforcing effects of the substance or behavior to an increasing loss of control over the behavior or drug intake, thus developing into habitual actions [36, 37]. Habitual actions are rather automatic and disconnected from their possibly adverse outcomes. This explains why addictive disorders are characterized by persistent relapse rates over time despite severe negative consequences [38]. Despite the conscious choice to decrease or stop the drug use or compulsive behavior, it can be almost unattainable to remain abstinent over time for many individuals [39, 40]. Habitual and compulsive behavior in the context of addiction can be triggered by cues that are associated with the substance or behavior in question as well as stressful or negative events [41]. In that context, experiential avoidance of states of negative mood or anxiety can drive individuals to cope through substance use or behavioral patterns, which can become habitual or even compulsory in the course of addiction; also, avoidance of imminent states of withdrawal could instigate relapse [42-45]. For people with addictive disorders, drug cues are imbued with incentive salience through conditioning processes and thereby become more salient than natural rewards [46, 47]. At the same time, the responsiveness to natural rewards is blunted [48]. These processes both drive increased drug intake as a means of maintaining hedonic equilibrium. Thus, in a kind of vicious circle, the attempt to preserve a dwindling sense of well-being through increased drug use can further dysregulate reward system function and exacerbate dysphoria, drug-related cuereactivity, and craving [49]. In addition, deficits in top-down cognitive control further augment the impact of craving on addictive behavior or substance intake [50]. This expands into impulsive choice behavior that is manifested as discounting of delayed rewards which has been associated with the severity of various addictive disorders [51].

Based on this hypothetical model of the emergence and course of addictive disorders, the following section aims at summarizing previous findings on the working mechanisms of MBIs and mindfulness in a broader context (Fig. 1).

\section{Restructuring of Responses to Drug and Natural Reward Cues}

Craving as an overwhelmingly strong urge is often evoked by exposure to addiction-related cues and can trigger averse physical and physiological responses as well as the strong desire to carry out the behavior in question [52]. It has been suggested that mindfulness can alleviate cue-induced craving in response to addiction cues. In favor of this notion, Westbrook et al. [53] found that mindful attention during the exposure to cigarette-related images reduced self-reported as well as neuronal measures of cue-induced craving in treatment-seeking smokers. In addition, reduced functional connectivity between the subgenual anterior cingulate cortex (sgACC) and other regions such as insula and ventral striatum might reflect reductions of craving-associated neurocircuitry when confronted with addiction-related cues. In line with that, a review of acceptance- and mindfulness-based approaches suggests that decoupling — reduction of the associations between different internal experiences or explicit behavior might be a central underlying mechanism of MBIs in the treatment of addiction [54].

In a small pilot study, it was found that smokers that underwent the MORE protocol showed significantly reduced smoking as well as increased positive affect. Functional magnetic resonance imaging (fMRI) revealed decreased neuronal cue reactivity to cigarettes in the ventral striatum (VS) as well as medial prefrontal cortex (mPFC) coupled with increased responsivity within that same circuit during savoring of natural healthy rewards [55] — suggesting that MORE was restructuring reward processes in the brain. Furthermore, cue-induced posterior cingulate cortical (PCC) activation was significantly linked to decreased cigarette consumption in a group of smokers that received an app-based MBI [56]. 
Fig. 1 Proposed processes that drive addictive disorders. Excessive cue-reactivity and blunted natural reward responsiveness as well as stress susceptibility, negative affect, and decreased top-down control making that in turn can lead to substance use or behavior enhance habitual decisionautomatic or even compulsive

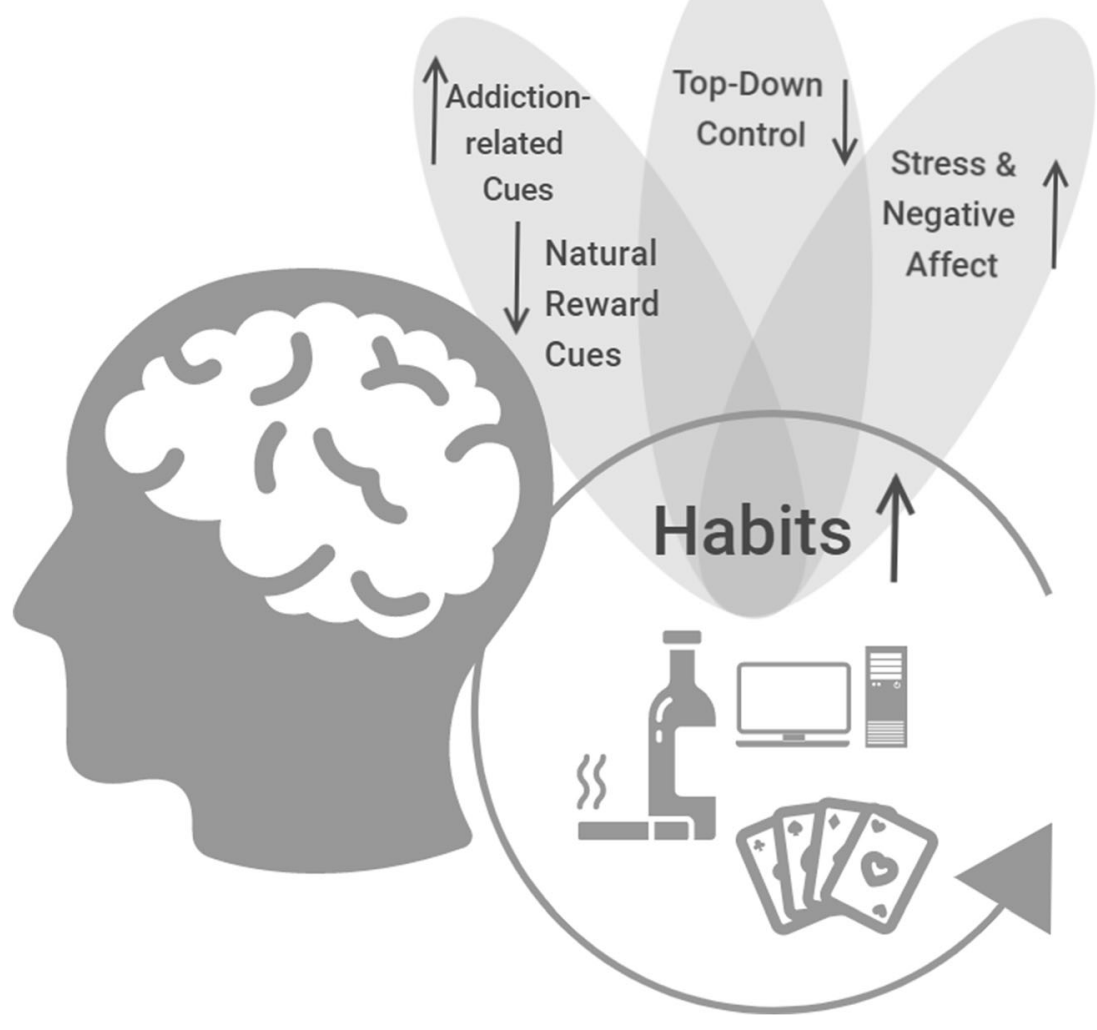

Given the risk of developing substance use disorder during chronic opioid therapy, a sample of prescription opioid users either underwent a support group control intervention or participated in 8 weeks of MORE. Next to decreased quantified opioid misuse and craving, the MBI was associated with less self-reported cue-reactivity towards opioid images, decelerated heart rate (HR), and increased heart rate variability (HRV). In addition, cardiac-autonomic reactivity to natural rewards was more pronounced in the treatment group $[57,58]$. In line with these findings, another cohort of opioid users was assessed after 8 weeks of MORE and cue-reactivity was measured on a neurophysiological level via electroencephalogram (EEG) $[59,60]$. MORE was associated with a decrease in late positive potential (LPP) towards opioid cues, indicating a reduction of cue-reactivity. On the other hand, responsiveness towards natural rewards was increased compared to the control group. Recently, salivation was found to be an adequate marker of cue-reactivity and the application of MORE led to reduced subjective craving as well as salivation in response to substance cues in opioid users [61]. Taken together, these data provide support for the hypothesis of restructuring reward processing, which asserts that MBIs shift valuation from drug-related rewards back to natural rewards, and in so doing, reduce craving and addictive behavior [62].

\section{Top-Down Control}

The influence of craving through cue-conditioning has even more impact on the manifestation and course of addictive disorders when paired with a decreasing capacity for behavioral inhibition [63]. Lack of top-down control might lead to a variety of maladaptive behaviors such as risk-taking, struggling with unhealthy choices, and the need for instant gratification through external rewards [50], albeit strong withdrawal symptoms can also account for the desire for reward, be it money to buy drugs or drug consumption itself [45]. Neuroscientific research has shown that decreased self-control can be associated with impairments in prefrontal neurocircuitry that has been affected by striatal neuroadaptations or even direct neurotoxic effects in the case of SUD $[64,65]$. Self-control can be trained, however, as a vast amount of research suggests and mindfulness might improve executive function through e.g. emotion regulation $[66,67]$.

In line with this, it was found that a brief mindfulness intervention led to reduced systolic blood pressure and increased error monitoring in a flanker task [68]. Mindfulness mediation also had positive effects on behavioral inhibition, which were associated with improved conflict and response monitoring measured by neurophysiological parameters in EEG $[69,70]$. Neuroimaging studies also indicate neural change in prefrontal cognitive control areas associated with mindfulness training: 
Several studies found that mindfulness training increased resting state connectivity between regions of the default mode network and prefrontal cortical areas, which are associated with executive function that contribute to top-down control $[71,72]$. Additionally, increases in prefrontal activation during an executive attention task, white matter volume, and increased glutamate metabolism in prefrontal regions such as the anterior cingulate cortex were associated with brief mindfulness interventions [73, 74].

Polysubstance users that received an MBI next to TAU exhibited improved working memory abilities as well as goal-directed control and increased reflected decision-making, in comparison to a control group [75]. In prescription opioid users with chronic pain conditions, treatment with MORE led to decreased errors of commission in an emotional Go/NoGo task when faced with pain-related distractors. Emotional response inhibition was furthermore correlated with the length of mindfulness practice as well as nonreactivity and reduced pain severity at follow-up [76].

In smokers, it was found that an MBI normalized activation in a self-control network comprised of the $\mathrm{ACC}$ and $\mathrm{mPFC}$, and that those neural alterations were linked to improved emotional regulation control [77]. A brief MBI also led to enhanced response inhibition indicated by neurophysiological markers during an EEG recorded Go/NoGo task in smokers [78].

In participants with internet gaming disorder (IGD), MORE treatment led to reduced maladaptive gamingrelated cognitions, and this reduction mediated decreases in craving and IGD severity [79]. The authors suggest that mindfulness strengthens metacognitive awareness of habitual internet gaming by involvement of top-down cognitive control.

Among opioid misusers, MORE has been shown to increase inhibitory control in the face of negative emotional distractors in an Emotional Go/NoGo Task [80], and to modify addiction-related attentional bias among people with alcohol use disorder [81] and those engaged in opioid misuse [82]. In addition, MORE may enhance self-regulatory strength and self-control over opioid use as indicted by increases in HRV [83] as well as enhanced endogenous theta stimulation in the prefrontal cortex during active mindfulness meditation [84]. These data indicate that MORE may increase cognitive control in the face of perturbations evoked by motivationally salient, drug-associated stimuli.

\section{Stress and Negative Affect}

In addictive disorders, reward seeking initially may occur for its positively reinforced value but over time, the behavior can shift to avoidance of negative reinforcement. This increases the relapse risk immensely as this negative affective state is most prominent in the withdrawal stage [45]. Negative affect is directly linked to enhanced reactivity in the brain's response to stressors [63].

Early studies on the effects of mindfulness meditation on distress and negative affect have shown that practicing mindfulness meditation can lead to reduced distress that is mediated by a decrease in rumination [85]. After a MBI, participants also improved in terms of bias towards negative emotional stimuli, while emotion processing in general was decreased [86]. Participants of a brief MBI also showed significant decreases in negative affect and state anxiety [87], as well as increased positive affect and a reduction of subjectively perceived stress that was linked to decreases in cortisol levels [88]. Neuroimaging studies furthermore revealed structural and functional alterations associated with mindfulness meditation training. Low-frequency amplitude changes in a region of the default mode network (DMN) were directly linked to a reduction of depression scores, indicating a positive effect of mindfulness on mood [89].

Ecological momentary assessments (EMA) have been used to examine the effect of MBIs on real-time affective experiences. In chronic pain patients with opioid use, MORE led to significant improvements in the patients' pain perception as well as positive affect. EMA confirmed that positive affect regulation was increased during treatment with MORE, and that positive affect was associated with reduced risk for opioid abuse [90]. In another EMA study, opioid use disorder patients reported increased self-control over craving as well as improvements in stress and positive affect. In addition, positive affect was associated with reduced craving in MORE participants [91]. In SUD patients, reduced stress as an outcome of MBRP also positively impacted on post-treatment substance use as a mediator [92]. In a recent study, following an ultra-brief MBI, stress-induced mood worsening as well as alcohol seeking was attenuated, while subjective mood improved in comparison to baseline. However, the reduction of stress-induced alcohol seeking was less pronounced in participants with more severe alcohol problems [93].

Another recent physiological study revealed that MBRP in SUD patients led to higher cardiac vagal control reflected by higher heart rate variability (HRV) and lower anxiogenic stress reactivity [94]. In deprived smokers that were exposed to a stressor, a brief MBI decreased the anxiogenic stress reactivity as indicated by subjective measures, but a buffering effect on physiological stress responses could not be discovered [95].

Neuroimaging also suggests that reduced stress reactivity might underlie some aspects of the efficacy of MBIs in addictive disorders. An fMRI study in smokers revealed that posttreatment reductions in smoking were linked to decreased neuronal activation in the amygdala and insula in response to stress. Moreover, these changes were greater in participants that received MBI [96]. 
While numerous studies have investigated how MBIs effectively target stress reactivity and negative affect, experiential avoidance has been identified as another driver of addictive disorders that might be commonly targeted by all MBIs. Substance use and other addictive behaviors (e.g., gambling, binge eating) may function as a means of avoiding aversive emotions and other internal experiences, which can lead to the initiation and maintenance of addictive disorders [44]. Commonly, MBIs aim to change how individuals respond to distress by increasing acceptance cognitive decentering, and other objective, non-judging responses while decreasing avoidance and suppression of negative emotions related to addictive behavior or substance use [17]. In the light of this, it was suggested that reducing high levels of smoking-specific experiential avoidance would decouple the urge to smoke from experience of internal distress [97]. Clinical studies support this notion. In addition to reduce cigarette use, participants of a mindfulness training intervention exhibited a decreased association between craving and smoking [98]. Furthermore, participation in an intensive meditation class was related to significant decreases in avoidance of thoughts, which partially mediated the reduction in post-treatment alcohol use in an incarcerated population [99]. Comparing an online-based ACT intervention with a widely accessed smoking cessation website, ACT participants exhibited significantly larger cessation rates that were mediated by increase of acceptance of physical, cognitive, and emotional smoking cues [100].

Altogether, the previous sections of this review show that different evidence-based mechanisms have been proposed to elucidate the pathways by which MBI and mindfulness conceptually impact the course of addictive disorders and abstinence. Consistent with current theories of addictive disorders, these proposals advocate that MBIs reduce cue-reactivity, attenuate cognitive control abilities, decrease stress-reactivity and negative affect as well as increasing acceptance of emotional states, and alleviate corresponding reactive behavior.

\section{Augmented Mindfulness}

Consistent with the growing popularity of mindfulness research, latest research has also investigated the effects of add-on or augmented interventions that aim at increasing the therapeutic efficacy of MBIs in addictive disorders. For instance, ketamine, a dissociative anesthetic, has been suggested to disrupt stimulant self-administration in cocaine users for a prolonged period and suggested to increase the efficacy of behavioral interventions $[101,102]$. In a pilot study, the combination of an MBI with a single ketamine infusion led to decreases of treatment dropout as well as craving scores compared to the MBI alone [103]. However, neuromodulation with transcranial direct current stimulation (tDCS) in addition to an MBI in AUD participants has shown that, although the
MBI was effective in reducing drinking as well as cue-reactivity, the stimulation did not improve the efficacy of the treatment [35].

Study protocols indicate that further technologically advanced methods have been considered to be effective in augmenting the effect of MBIs as well. Currently undergoing research investigates the effect of virtual reality cueexposure in addition to an MBI in methamphetamine use disorder patients [104]. Pursuant to this, real-time fMRI neurofeedback in addition to an MBI is presently examined in patients with AUD [105].

\section{Discussion}

Mindfulness practices have been growing in popularity over the last decade and simultaneously emergent research started to examine the efficacy and underlying mechanisms of MBIs in the context of mental health [106]. MBIs have also been implemented in the context of behavioral and substance-related addictive disorders, and results have been very promising $[20,21]$. Two meta-analyses, however, concluded that MBIs are not of superior efficacy as already implemented treatment approaches [12, 24]. As mindfulness research is still in its infancy, more longitudinal RCTs with large sample sizes are needed to confirm the clinical use in addictive disorders. Emergent with the neurocognitive research on the causes and maintenance of addiction, several processes have been highlighted to lead to habitual or even compulsive behavior or substance use $[36,37,63]$. Taking up the literature on cue-reactivity, cognitive control as well as stress and negative affect, among others, researchers have been embedding neurocognitive tasks or stress challenges into their applied research on MBIs. In addition, brief mindfulness trainings have been investigated to elucidate the direct effect of mindfulness meditation on cognitive functioning or substance use [70, 93]. The assessment of brief mindfulness training on different cognitive and neurobiological variables is crucial, as conclusions regarding specific mechanistical effects are challenging because MBIs are characteristically composed of a variety of interventional techniques [22]. For instance, MBRP combines mindfulness meditation practices with cognitive behavioral relapse prevention treatment [6], while MORE integrates training in mindfulness with reappraisal and savoring skills [7]. In addition to the neurocognitive alterations induced by MBIs, it is also important to consider that their efficacy might depend on the target group. For instance, it was suggested that participants with lower substance use severity are more prone to profit from MBIs [93, 107]. Another crucial matter in the clinical practice of MBIs is suboptimal compliance rates that have been found to be lower than in relapse prevention alone [35, 108]. MBI participants have been seen to have problems with practicing mindfulness on a regular basis, which Witkiewitz et al. [35] hypothetically link to potential shortfalls in executive cognitive functioning in some patients 
with addictive disorders. This limitation, however, might possibly be overcome through the use of app-based MBI programs, which are additionally cost-effective, accessible, and personalizable to increase compliance. In smokers, they have been shown to be effective in reducing craving-induced smoking [56, 109]. Moreover, augmented MBIs are currently under investigation and hold promise in utilizing and combining mindfulness with other auspicious treatment approaches [103].

In sum, large, robust, and controlled clinical trials are needed to draw conclusions on the efficacy as well as cognitive and neurobiological mechanisms underlying mindfulness as an interventional approach in addictive disorders. Especially research in the field of behavioral addictions is still scarce. However, in light of this review, we feel the future of MBIs in the field of addiction therapy is promising.

Funding Open Access funding enabled and organized by Projekt DEAL. This work was partially supported by the German Research Foundation (DFG, Project-ID 402170461 - TRR 265; 390688087 - EXC 2049).

\section{Declarations}

Conflict of Interest The authors declare no competing interests.

Open Access This article is licensed under a Creative Commons Attribution 4.0 International License, which permits use, sharing, adaptation, distribution and reproduction in any medium or format, as long as you give appropriate credit to the original author(s) and the source, provide a link to the Creative Commons licence, and indicate if changes were made. The images or other third party material in this article are included in the article's Creative Commons licence, unless indicated otherwise in a credit line to the material. If material is not included in the article's Creative Commons licence and your intended use is not permitted by statutory regulation or exceeds the permitted use, you will need to obtain permission directly from the copyright holder. To view a copy of this licence, visit http://creativecommons.org/licenses/by/4.0/.

\section{References}

1. Association AP. Diagnostic and statistical manual of mental disorders (DSM-5®). American Psychiatric Pub; 2013.

2. Kassani A, Niazi M, Hassanzadeh J, Menati R. Survival analysis of drug abuse relapse in addiction treatment centers. International journal of high risk behaviors \& addiction. 2015;4(3).

3. Liu S, Dolan RJ, Heinz A. Translation of computational psychiatry in the context of addiction. JAMA psychiatry. 2020;77:1099. https://doi.org/10.1001/jamapsychiatry.2020.1637.

4. Carroll KM, Onken LS. Behavioral therapies for drug abuse. Am J Psychiatr. 2005;162(8):1452-60.

5. Lee EB, An W, Levin ME, Twohig MP. An initial meta-analysis of Acceptance and Commitment Therapy for treating substance use disorders. Drug Alcohol Depend. 2015;155:1-7. https://doi. org/10.1016/j.drugalcdep.2015.08.004.
6. Bowen S, Chawla N, Grow J, Marlatt GA. Mindfulness-based relapse prevention for addictive behaviors: a clinician's guide. Guilford Publications; 2021.

7. Garland EL, Baker AK, Riquino MR, Priddy SE. Mindfulnessoriented recovery enhancement. Handb mindfulness-based program mindfulness Interv from Educ to heal Ther Abingdon: Routledge. 2019.

8. Garland EL. Restructuring reward processing with mindfulnessoriented recovery enhancement: novel therapeutic mechanisms to remediate hedonic dysregulation in addiction, stress, and pain. Ann N Y Acad Sci. 2016;1373(1):25-37. https://doi.org/10. 1111/nyas.13034.

9. Priddy SE, Howard MO, Hanley AW, Riquino MR, FribergFelsted K, Garland EL. Mindfulness meditation in the treatment of substance use disorders and preventing future relapse: neurocognitive mechanisms and clinical implications. Subst Abus Rehabil. 2018;9:103-14. https://doi.org/10.2147/SAR. S145201.

10. Kabat-Zinn J. Wherever you go, there you are: mindfulness meditation in everyday life. Hachette Books; 2009.

11. Cavicchioli M, Movalli M, Maffei C. The clinical efficacy of mindfulness-based treatments for alcohol and drugs use disorders: a meta-analytic review of randomized and nonrandomized controlled trials. Eur Addict Res. 2018;24:137-62. https://doi.org/10. 1159/000490762.

12. Byrne SP, Haber P, Baillie A, Costa DSJ, Fogliati V, Morley K. Systematic reviews of mindfulness and acceptance and commitment therapy for alcohol use disorder: should we be using third wave therapies? Alcohol and alcoholism (Oxford, Oxfordshire). 2019;54(2):159-66. https://doi.org/10.1093/alcalc/agy089.

13. Sancho M, De Gracia M, Rodríguez RC, Mallorquí-Bagué N, Sánchez-González J, Trujols J, et al. Mindfulness-based interventions for the treatment of substance and behavioral addictions: a systematic review. Frontiers in Psychiatry. 2018;9(95). https://doi. org/10.3389/fpsyt.2018.00095.

14. Ludwig DS, Kabat-Zinn J. Mindfulness in medicine. Jama. 2008;300(11):1350-2.

15. Kabat-Zinn J. Wherever you go, there you are: mindfulness meditation in everyday life. 1st ed. New York: Hyperion; 1994.

16. Kiken LG, Garland EL, Bluth K, Palsson OS, Gaylord SA. From a state to a trait: trajectories of state mindfulness in meditation during intervention predict changes in trait mindfulness. Personal Individ Differ. 2015;81:41-6.

17. Witkiewitz K, Marlatt GA, Walker D. Mindfulness-based relapse prevention for alcohol and substance use disorders. J Cogn Psychother. 2005;19(3):211-28.

18. Hayes SC, Hofmann SG. The third wave of cognitive behavioral therapy and the rise of process-based care. World Psychiatry. 2017;16(3):245-6.

19. Hayes SC, Strosahl KD, Wilson KG. Acceptance and commitment therapy. Washington DC: American Psychological Association; 2009.

20. Li W, Howard MO, Garland EL, McGovern P, Lazar M. Mindfulness treatment for substance misuse: a systematic review and meta-analysis. J Subst Abus Treat. 2017;75:62-96. https:// doi.org/10.1016/j.jsat.2017.01.008.

21. Grant S, Colaiaco B, Motala A, Shanman R, Booth M, Sorbero M, et al. Mindfulness-based relapse prevention for substance use disorders: a systematic review and meta-analysis. J Addict Med. 2017;11(5):386-96. https://doi.org/10.1097/adm. 0000000000000338 .

22. Korecki JR, Schwebel FJ, Votaw VR, Witkiewitz K. Mindfulnessbased programs for substance use disorders: a systematic review 
of manualized treatments. Subst Abuse Treat Prev Policy. 2020;15(1):51. https://doi.org/10.1186/s13011-020-00293-3.

23. Maglione MA, Maher AR, Ewing B, Colaiaco B, Newberry S, Kandrack R, et al. Efficacy of mindfulness meditation for smoking cessation: a systematic review and meta-analysis. Addict Behav. 2017;69:27-34. https://doi.org/10.1016/j.addbeh.2017.01.022.

24. Osaji J, Ojimba C, Ahmed S. The use of acceptance and commitment therapy in substance use disorders: a review of literature. J Clin Med Res. 2020;12(10):629-33. https://doi.org/10.14740/ jocmr4311.

25. Maynard BR, Wilson AN, Labuzienski E, Whiting SW. Mindfulness-based approaches in the treatment of disordered gambling: a systematic review and meta-analysis. Res Soc Work Pract. 2015;28(3):348-62. https://doi.org/10.1177/ 1049731515606977.

26. Shonin E, Van Gordon W, Griffiths M. Mindfulness as a treatment for behavioural addiction. Journal of Addiction Research \& Therapy. 2014;5(1).

27. McIntosh CC, Crino RD, O'Neill K. Treating problem gambling samples with cognitive behavioural therapy and mindfulnessbased interventions: a clinical trial. J Gambl Stud. 2016;32(4): 1305-25. https://doi.org/10.1007/s10899-016-9602-1.

28. Lan Y, Ding JE, Li W, Li J, Zhang Y, Liu M, et al. A pilot study of a group mindfulness-based cognitive-behavioral intervention for smartphone addiction among university students. J Behav Addict. 2018;7(4):1171-6. https://doi.org/10.1556/2006.7.2018.103.

29. Duffy A, Dawson DL. das Nair R. Pornography addiction in adults: a systematic review of definitions and reported impact. J Sex Med. 2016;13(5):760-77. https://doi.org/10.1016/j.jsxm. 2016.03.002.

30. Chevinsky JD, Wadden TA, Chao AM. Binge eating disorder in patients with type 2 diabetes: diagnostic and management challenges. Diabetes, metabolic syndrome and obesity : targets and therapy. 2020;13:1117-31. https://doi.org/10.2147/dmso. S213379.

31. Ghazanfarpour M, Babakhanian M, Keshtkar A, Kiani M. A systematic review and meta-analysis of three clinical trials with Acceptance and Commitment Therapy for problematic pornography use. Alcoholism and Drug Addiction/Alkoholizm i Narkomania. 33(3):275-82.

32. Godfrey KM, Gallo LC, Afari N. Mindfulness-based interventions for binge eating: a systematic review and meta-analysis. J Behav Med. 2015;38(2):348-62. https://doi.org/10.1007/s10865-0149610-5.

33. McKeith CFA, Rock AJ, Clark GI. Trait mindfulness, problemgambling severity, altered state of awareness and urge to gamble in poker-machine gamblers. J Gambl Stud. 2017;33(2):617-32. https://doi.org/10.1007/s10899-016-9635-5.

34. von Hammerstein C, Miranda R, Aubin HJ, Romo L, Khazaal Y, Benyamina A, et al. Mindfulness and cognitive training in a CBTresistant patient with gambling disorder: a combined therapy to enhance self-control. J Addict Med. 2018;12(6):484-9. https://doi. org/10.1097/adm.0000000000000433.

35. Witkiewitz K, Stein ER, Votaw VR, Wilson AD, Roos CR, Gallegos SJ, et al. Mindfulness-based relapse prevention and transcranial direct current stimulation to reduce heavy drinking: a double-blind sham-controlled randomized trial. Alcohol Clin Exp Res. 2019;43(6):1296-307. https://doi.org/10.1111/acer. 14053.

36. Koob GF, Volkow ND. Neurobiology of addiction: a neurocircuitry analysis. Lancet Psychiatry. 2016;3(8):760-73. https://doi.org/10.1016/s2215-0366(16)00104-8.
37. Heinz A, Kiefer F, Smolka MN, Endrass T, Beste C, Beck A, et al. Addiction Research Consortium: losing and regaining control over drug intake (ReCoDe)-from trajectories to mechanisms and interventions. Addict Biol. 2020;25(2):e12866. https://doi.org/10. 1111/adb.12866.

38. Beck A, Rosenthal A, Auriacombe M, Romanczuk-Seiferth N. (Neuro)therapeutic approaches in the field of alcohol use disorders. Current Addiction Reports. 2020;7(3):252-9. https://doi.org/ 10.1007/s40429-020-00324-w.

39. Everitt BJ, Robbins TW. From the ventral to the dorsal striatum: devolving views of their roles in drug addiction. Neurosci Biobehav Rev. 2013;37(9 Pt A):1946-54. https://doi.org/10. 1016/j.neubiorev.2013.02.010.

40. Volkow ND, Morales M. The brain on drugs: from reward to addiction. Cell. 2015;162(4):712-25. https://doi.org/10.1016/j. cell.2015.07.046.

41. Bossert JM, Marchant NJ, Calu DJ, Shaham Y. The reinstatement model of drug relapse: recent neurobiological findings, emerging research topics, and translational research. Psychopharmacology. 2013;229(3):453-76. https://doi.org/10.1007/s00213-013-3120$\mathrm{y}$.

42. Hogarth L. Addiction is driven by excessive goal-directed drug choice under negative affect: translational critique of habit and compulsion theory. Neuropsychopharmacology : official publication of the American College of Neuropsychopharmacology. 2020;45(5):720-35. https://doi.org/10.1038/s41386-020-0600-8.

43. Hogarth L, Hardy L, Mathew AR, Hitsman B. Negative moodinduced alcohol-seeking is greater in young adults who report depression symptoms, drinking to cope, and subjective reactivity. Exp Clin Psychopharmacol. 2018;26(2):138-46. https://doi.org/ 10.1037/pha0000177.

44. Levin ME, Lillis J, Seeley J, Hayes SC, Pistorello J, Biglan A. Exploring the relationship between experiential avoidance, alcohol use disorders, and alcohol-related problems among first-year college students. J Am Coll Heal. 2012;60(6):443-8. https://doi. org/10.1080/07448481.2012.673522.

45. Heinz A, Löber S, Georgi A, Wrase J, Hermann D, Rey ER, et al. Reward craving and withdrawal relief craving: assessment of different motivational pathways to alcohol intake. Alcohol and alcoholism (Oxford, Oxfordshire). 2003;38(1):35-9. https://doi.org/ 10.1093/alcalc/agg005.

46. Berridge $\mathrm{KC}$, Robinson TE. Liking, wanting, and the incentivesensitization theory of addiction. The American psychologist. 2016;71(8):670-9. https://doi.org/10.1037/amp0000059.

47. Beck A, Schlagenhauf F, Wüstenberg T, Hein J, Kienast T, Kahnt $\mathrm{T}$, et al. Ventral striatal activation during reward anticipation correlates with impulsivity in alcoholics. Biol Psychiatry. 2009;66(8): 734-42. https://doi.org/10.1016/j.biopsych.2009.04.035.

48. Wrase J, Schlagenhauf F, Kienast T, Wüstenberg T, Bermpohl F, Kahnt T, et al. Dysfunction of reward processing correlates with alcohol craving in detoxified alcoholics. Neuroimage. 2007;35(2): 787-94. https://doi.org/10.1016/j.neuroimage.2006.11.043.

49. Koob GF, Le Moal M. Drug addiction, dysregulation of reward, and allostasis. Neuropsychopharmacology : official publication of the American College of Neuropsychopharmacology. 2001;24(2): 97-129.

50. Volkow ND, Fowler JS. Addiction, a disease of compulsion and drive: involvement of the orbitofrontal cortex. Cerebral cortex (New York, NY : 1991). 2000;10(3):318-25. https://doi.org/10. 1093/cercor/10.3.318

51. Amlung M, Vedelago L, Acker J, Balodis I, MacKillop J. Steep delay discounting and addictive behavior: a meta-analysis of 
continuous associations. Addiction. 2017;112(1):51-62. https:// doi.org/10.1111/add.13535.

52. Carter BL, Tiffany ST. Meta-analysis of cue-reactivity in addiction research. Addiction. 1999;94(3):327-40.

53. Westbrook C, Creswell JD, Tabibnia G, Julson E, Kober H, Tindle HA. Mindful attention reduces neural and self-reported cue-induced craving in smokers. Soc Cogn Affect Neurosci. 2013;8(1):73-84. https://doi.org/10.1093/scan/nsr076.

54. Levin ME, Luoma JB, Haeger JA. Decoupling as a mechanism of change in mindfulness and acceptance: a literature review. Behav Modif. 2015;39(6):870-911. https://doi.org/10.1177/ 0145445515603707.

55. Froeliger B, Mathew AR, McConnell PA, Eichberg C, Saladin $\mathrm{ME}$, Carpenter MJ, et al. Restructuring reward mechanisms in nicotine addiction: a pilot fMRI study of mindfulness-oriented recovery enhancement for cigarette smokers. Evidence-based complementary and alternative medicine : eCAM. 2017;2017: 7018014-0. https://doi.org/10.1155/2017/7018014.

56. Janes AC, Datko M, Roy A, Barton B, Druker S, Neal C, et al. Quitting starts in the brain: a randomized controlled trial of appbased mindfulness shows decreases in neural responses to smoking cues that predict reductions in smoking. Neuropsychopharmacology : official publication of the American College of Neuropsychopharmacology. 2019;44(9):1631-8. https://doi.org/10. 1038/s41386-019-0403-y.

57. Garland EL, Froeliger B, Howard MO. Effects of MindfulnessOriented Recovery Enhancement on reward responsiveness and opioid cue-reactivity. Psychopharmacology. 2014;231(16):3229 38. https://doi.org/10.1007/s00213-014-3504-7.

58. Garland EL, Howard MO, Zubieta JK, Froeliger B. Restructuring hedonic dysregulation in chronic pain and prescription opioid misuse: effects of mindfulness-oriented recovery enhancement on responsiveness to drug cues and natural rewards. Psychother Psychosom. 2017;86(2):111-2. https://doi.org/10.1159/000453400.

59. Garland EL, Atchley RM, Hanley AW, Zubieta JK, Froeliger B. Mindfulness-Oriented Recovery Enhancement remediates hedonic dysregulation in opioid users: neural and affective evidence of target engagement. Sci Adv. 2019;5(10):eaax1569. https://doi. org/10.1126/sciadv.aax 1569 .

60. Garland EL, Froeliger B, Howard MO. Neurophysiological evidence for remediation of reward processing deficits in chronic pain and opioid misuse following treatment with Mindfulness-Oriented Recovery Enhancement: exploratory ERP findings from a pilot RCT. J Behav Med. 2015;38(2):327-36. https://doi.org/10.1007/ s10865-014-9607-0.

61. Hanley AW, Garland EL. Salivary measurement and mindfulnessbased modulation of prescription opioid cue-reactivity. Drug Alcohol Depend. 2020;217:108351. https://doi.org/10.1016/j. drugalcdep.2020.108351.

62. Garland E. Restructuring reward processing with MindfulnessOriented Recovery Enhancement: novel therapeutic mechanisms to remediate hedonic dysregulation in addiction, stress, and pain. Ann N Y Acad Sci. 2016;1373(1):25-37.

63. Volkow ND, Michaelides M, Baler R. The neuroscience of drug reward and addiction. Physiol Rev. 2019;99(4):2115-40. https:// doi.org/10.1152/physrev.00014.2018.

64. Tang YY, Posner MI, Rothbart MK, Volkow ND. Circuitry of self-control and its role in reducing addiction. Trends Cogn Sci. 2015;19(8):439-44. https://doi.org/10.1016/j.tics.2015.06.007.

65. Rosenthal A, Beck A, Zois E, Vollstädt-Klein S, Walter H, Kiefer $\mathrm{F}$, et al. Volumetric prefrontal cortex alterations in patients with alcohol dependence and the involvement of self-control. Alcohol
Clin Exp Res. 2019;43(12):2514-24. https://doi.org/10.1111/acer. 14211.

66. Tang Y-Y, Tang R, Posner MI. Mindfulness meditation improves emotion regulation and reduces drug abuse. Drug Alcohol Depend. 2016;163:S13-S8. https://doi.org/10.1016/j.drugalcdep. 2015.11.041.

67. Prakash RS, Hussain MA, Schirda B. The role of emotion regulation and cognitive control in the association between mindfulness disposition and stress. Psychol Aging. 2015;30(1):160-71.

68. Larson MJ, Steffen PR, Primosch M. The impact of a brief mindfulness meditation intervention on cognitive control and errorrelated performance monitoring. Front Hum Neurosci. 2013;7: 308. https://doi.org/10.3389/fnhum.2013.00308.

69. Pozuelos JP, Mead BR, Rueda MR, Malinowski P. Short-term mindful breath awareness training improves inhibitory control and response monitoring. Prog Brain Res. 2019;244:137-63. https://doi.org/10.1016/bs.pbr.2018.10.019.

70. Quaglia JT, Zeidan F, Grossenbacher PG, Freeman SP, Braun SE, Martelli A, et al. Brief mindfulness training enhances cognitive control in socioemotional contexts: behavioral and neural evidence. PLoS One. 2019;14(7):e0219862. https://doi.org/10.1371/ journal.pone.0219862.

71. Creswell JD, Taren AA, Lindsay EK, Greco CM, Gianaros PJ, Fairgrieve A, et al. Alterations in resting-state functional connectivity link mindfulness meditation with reduced interleukin-6: a randomized controlled trial. Biol Psychiatry. 2016;80(1):53-61. https://doi.org/10.1016/j.biopsych.2016.01.008.

72. Taren AA, Gianaros PJ, Greco CM, Lindsay EK, Fairgrieve A, Brown KW, et al. Mindfulness meditation training and executive control network resting state functional connectivity: a randomized controlled trial. Psychosom Med. 2017;79(6):674-83. https:// doi.org/10.1097/psy.0000000000000466.

73. Tang YY, Askari P, Choi C. Brief mindfulness training increased glutamate metabolism in the anterior cingulate cortex. Neuroreport. 2020;31(16):1142-5. https://doi.org/10.1097/wnr. 0000000000001527.

74. Tang YY, Lu Q, Geng X, Stein EA, Yang Y, Posner MI. Shortterm meditation induces white matter changes in the anterior cingulate. Proc Natl Acad Sci U S A. 2010;107(35):15649-52. https://doi.org/10.1073/pnas.1011043107.

75. Valls-Serrano C, Caracuel A, Verdejo-Garcia A. Goal Management Training and Mindfulness Meditation improve executive functions and transfer to ecological tasks of daily life in polysubstance users enrolled in therapeutic community treatment. Drug Alcohol Depend. 2016;165:9-14. https://doi.org/10.1016/j. drugalcdep.2016.04.040.

76. Garland EL, Bryan MA, Priddy SE, Riquino MR, Froeliger B, Howard MO. Effects of mindfulness-oriented recovery enhancement versus social support on negative affective interference during inhibitory control among opioid-treated chronic pain patients: a pilot mechanistic study. Annals of behavioral medicine : a publication of the Society of Behavioral Medicine. 2019;53(10):86576. https://doi.org/10.1093/abm/kay096.

77. Tang YY, Tang R, Posner MI. Mindfulness meditation improves emotion regulation and reduces drug abuse. Drug Alcohol Depend. 2016;163(Suppl 1):S13-8. https://doi.org/10.1016/j. drugalcdep.2015.11.041.

78. Andreu CI, Cosmelli D, Slagter HA, Franken IHA. Effects of a brief mindfulness-meditation intervention on neural measures of response inhibition in cigarette smokers. PLoS One. 2018;13(1): e0191661. https://doi.org/10.1371/journal.pone.0191661.

79. Li W, Garland EL, Howard MO. Therapeutic mechanisms of Mindfulness-Oriented Recovery Enhancement for internet 
gaming disorder: reducing craving and addictive behavior by targeting cognitive processes. J Addict Dis. 2018;37(1-2):5-13. https://doi.org/10.1080/10550887.2018.1442617.

80. Garland EL, Bryan MA, Priddy SE, Riquino MR, Froeliger B, Howard MO. Effects of mindfulness-oriented recovery enhancement versus social support on negative affective interference during inhibitory control among opioid-treated chronic pain patients: a pilot mechanistic study. Ann Behav Med. 2019;53(10):865-76.

81. Garland EL, Gaylord SA, Boettiger CA, Howard MO. Mindfulness training modifies cognitive, affective, and physiological mechanisms implicated in alcohol dependence: results of a randomized controlled pilot trial. J Psychoactive Drugs. 2010;42(2):177-92.

82. Garland EL, Baker AK, Howard MO. Mindfulness-oriented recovery enhancement reduces opioid attentional bias among prescription opioid-treated chronic pain patients. J Soc Soc Work Res. 2017;8(4):493-509.

83. Garland EL, Hudak J, Hanley AW, Nakamura Y. Mindfulnessoriented recovery enhancement reduces opioid dose in primary care by strengthening autonomic regulation during meditation. Am Psychol. 2020;75(6):840-52.

84. Hudak J, Hanley AW, Marchand WR, Nakamura Y, Yabko B, Garland EL. Endogenous theta stimulation during meditation predicts reduced opioid dosing following treatment with MindfulnessOriented Recovery Enhancement. Neuropsychopharmacology : official publication of the American College of Neuropsychopharmacology. 2021;46(4):836-43. https://doi.org/10. 1038/s41386-020-00831-4.

85. Jain S, Shapiro SL, Swanick S, Roesch SC, Mills PJ, Bell I, et al. A randomized controlled trial of mindfulness meditation versus relaxation training: effects on distress, positive states of mind, rumination, and distraction. Annals of behavioral medicine : a publication of the Society of Behavioral Medicine. 2007;33(1): 11-21. https://doi.org/10.1207/s15324796abm3301_2.

86. Wu R, Liu LL, Zhu H, Su WJ, Cao ZY, Zhong SY, et al. Brief mindfulness meditation improves emotion processing. Front Neurosci. 2019;13:1074. https://doi.org/10.3389/fnins.2019. 01074.

87. Bellosta-Batalla M, Del Carmen B-GM, Rodríguez-Arias M, Cebolla A, Pérez-Blasco J, Moya-Albiol L. Brief mindfulness session improves mood and increases salivary oxytocin in psychology students. Stress and health : journal of the International Society for the Investigation of Stress. 2020;36(4):469-77. https:// doi.org/10.1002/smi.2942.

88. Sousa GM, Lima-Araújo GL, Araújo DB, Sousa MBC. Brief mindfulness-based training and mindfulness trait attenuate psychological stress in university students: a randomized controlled trial. BMC psychology. 2021;9(1):21. https://doi.org/10.1186/ s40359-021-00520-x.

89. Yang CC, Barrós-Loscertales A, Li M, Pinazo D, Borchardt V, Ávila C, et al. Alterations in brain structure and amplitude of lowfrequency after 8 weeks of mindfulness meditation training in meditation-naïve subjects. Sci Rep. 2019;9(1):10977. https://doi. org/10.1038/s41598-019-47470-4.

90. Garland EL, Bryan CJ, Finan PH, Thomas EA, Priddy SE, Riquino MR, et al. Pain, hedonic regulation, and opioid misuse: modulation of momentary experience by Mindfulness-Oriented Recovery Enhancement in opioid-treated chronic pain patients. Drug Alcohol Depend. 2017;173(Suppl 1):S65-s72. https://doi. org/10.1016/j.drugalcdep.2016.07.033.

91. Garland EL, Hanley AW, Kline A, Cooperman NA. MindfulnessOriented Recovery Enhancement reduces opioid craving among individuals with opioid use disorder and chronic pain in medication assisted treatment: ecological momentary assessments from a stage 1 randomized controlled trial. Drug Alcohol Depend. 2019;203:61-5. https://doi.org/10.1016/j.drugalcdep.2019.07. 007.

92. Davis JP, Berry D, Dumas TM, Ritter E, Smith DC, Menard C, et al. Substance use outcomes for mindfulness based relapse prevention are partially mediated by reductions in stress: results from a randomized trial. J Subst Abus Treat. 2018;91:37-48. https://doi. org/10.1016/j.jsat.2018.05.002.

93. Shuai R, Bakou AE, Hardy L, Hogarth L. Ultra-brief breath counting (mindfulness) training promotes recovery from stressinduced alcohol-seeking in student drinkers. Addict Behav. 2020;102:106141. https://doi.org/10.1016/j.addbeh.2019.106141.

94. Carroll H, Lustyk MKB. Mindfulness-based relapse prevention for substance use disorders: effects on cardiac vagal control and craving under stress. Mindfulness. 2018;9(2):488-99. https://doi. org/10.1007/s12671-017-0791-1.

95. Paz R, Zvielli A, Goldstein P, Bernstein A. Brief mindfulness training de-couples the anxiogenic effects of distress intolerance on reactivity to and recovery from stress among deprived smokers. Behav Res Ther. 2017;95:117-27. https://doi.org/10.1016/j.brat. 2017.05.017.

96. Kober H, Brewer JA, Height KL, Sinha R. Neural stress reactivity relates to smoking outcomes and differentiates between mindfulness and cognitive-behavioral treatments. Neuroimage. 2017;151: 4-13. https://doi.org/10.1016/j.neuroimage.2016.09.042.

97. Minami H, Bloom EL, Reed KM, Hayes SC, Brown RA. The moderating role of experiential avoidance in the relationships between internal distress and smoking behavior during a quit attempt. Psychology of addictive behaviors : journal of the Society of Psychologists in Addictive Behaviors. 2015;29(2):400-7. https://doi.org/10.1037/adb0000030.

98. Elwafi HM, Witkiewitz K, Mallik S, Thornhill TA, Brewer JA. Mindfulness training for smoking cessation: moderation of the relationship between craving and cigarette use. Drug Alcohol Depend. 2013;130(1-3):222-9. https://doi.org/10.1016/j. drugalcdep.2012.11.015.

99. Bowen S, Witkiewitz K, Dillworth TM, Marlatt GA. The role of thought suppression in the relationship between mindfulness meditation and alcohol use. Addict Behav. 2007;32(10):2324-8. https://doi.org/10.1016/j.addbeh.2007.01.025.

100. Bricker J, Wyszynski C, Comstock B, Heffner JL. Pilot randomized controlled trial of web-based acceptance and commitment therapy for smoking cessation. Nicotine \& tobacco research : official journal of the Society for Research on Nicotine and Tobacco. 2013;15(10):1756-64. https://doi.org/10.1093/ntr/ntt056.

101. Dakwar E, Levin F, Foltin RW, Nunes EV, Hart CL. The effects of subanesthetic ketamine infusions on motivation to quit and cueinduced craving in cocaine-dependent research volunteers. Biol Psychiatry. 2014;76(1):40-6. https://doi.org/10.1016/j.biopsych. 2013.08.009.

102. Dakwar E, Hart CL, Levin FR, Nunes EV, Foltin RW. Cocaine selfadministration disrupted by the N-methyl-D-aspartate receptor antagonist ketamine: a randomized, crossover trial. Mol Psychiatry. 2017;22(1):76-81. https://doi.org/10.1038/mp.2016.39.

103. Dakwar E, Nunes EV, Hart CL, Foltin RW, Mathew SJ, Carpenter $\mathrm{KM}$, et al. A single ketamine infusion combined with mindfulness-based behavioral modification to treat cocaine dependence: a randomized clinical trial. Am J Psychiatry. 2019;176(11): 923-30. https://doi.org/10.1176/appi.ajp.2019.18101123.

104. Chen XJ, Wang DM, Zhou LD, Winkler M, Pauli P, Sui N, et al. Mindfulness-based relapse prevention combined with virtual reality cue exposure for methamphetamine use disorder: study 
protocol for a randomized controlled trial. Contemporary clinical trials. 2018;70:99-105. https://doi.org/10.1016/j.cct.2018.04.006.

105. Weiss F, Aslan A, Zhang J, Gerchen MF, Kiefer F, Kirsch P. Using mind control to modify cue-reactivity in AUD: the impact of mindfulness-based relapse prevention on real-time fMRI neurofeedback to modify cue-reactivity in alcohol use disorder: a randomized controlled trial. BMC psychiatry. 2020;20(1):309. https://doi.org/10.1186/s12888-020-02717-7.

106. Dossett ML, Fricchione GL, Benson H. A new era for mind-body medicine. N Engl J Med. 2020;382(15):1390-1. https://doi.org/ 10.1056/NEJMp1917461.

107. Roos CR, Bowen S, Witkiewitz K. Baseline patterns of substance use disorder severity and depression and anxiety symptoms moderate the efficacy of mindfulness-based relapse prevention. $\mathrm{J}$ Consult Clin Psychol. 2017;85(11):1041-51. https://doi.org/10. 1037/ccp0000249.
108. Bowen S, Witkiewitz K, Clifasefi SL, Grow J, Chawla N, Hsu SH, et al. Relative efficacy of mindfulness-based relapse prevention, standard relapse prevention, and treatment as usual for substance use disorders: a randomized clinical trial. JAMA psychiatry. 2014;71(5):547-56. https://doi.org/10.1001/jamapsychiatry. 2013.4546.

109. Garrison KA, Pal P, O’Malley SS, Pittman BP, Gueorguieva R, Rojiani R, et al. Craving to quit: a randomized controlled trial of smartphone app-based mindfulness training for smoking cessation. Nicotine Tob Res. 2020;22(3):324-31.

Publisher's Note Springer Nature remains neutral with regard to jurisdictional claims in published maps and institutional affiliations. 